\title{
PROTEIN EXPRESSION IN ARABIDOPSIS THALIANA AFTER CHRONIC CLINOROTATION
}

\author{
William C. Piastuch and Christopher S. Brown
}

Plant Space Biology Laboratory, The Bionetics Corporation, Kennedy Space Center, FL 32899, USA 


\section{Running Title: CHRONIC CLINOROTATION AND PROTEIN EXPRESSION}

Corresponding Author:

William C. Piastuch

Plant Space Biology Laboratory

The Bionetics Corporation

Mail Code BIO-3, Hangar L

Kennedy Space Center, FL 32899, USA 


\section{Summary}

Soluble protein expression in Arabidopsis thaliana L. (Heynh.) leaf and stem tissue was examined after chronic clinorotation. Seeds of Arabidopsis were germinated and plants grown to maturity on horizontal or vertical slow-rotating clinostats (1 rpm) or in stationary vertical control units. Total soluble proteins and in vivo-labeled soluble proteins isolated from these plants were analyzed by two-dimensional SDS PAGE and subsequent fluorography. Visual and computer analysis of the resulting protein patterns showed no significant differences in either total protein expression or in active protein synthesis between horizontal clinorotation and vertical controls in the Arabidopsis leaf and stem tissue. These results show chronic clinorotation does not cause gross changes in protein expression in Arabidopsis.

Key words: Arabidopsis thaliana, clinostat, gravity, protein pattern, SDSPAGE, stress

Abbreviations: SDS PAGE - sodium doedocyl sulfate polyacrylamide gel electrophoresis; DAP - days after planting. 


\section{Introduction}

Clinorotation subjects plants to a continually changing gravity vector. The net effect is the functional nullification of the directional component of gravity. Clinorotation is not a simulation of microgravity but does provide a mechanism to examine plants growing in an altered gravity environment that may reflect results obtained during actual space flights (Johnson and Tibbitts, 1968). Recent work demonstrated that membrane enzyme activities and protein turnover (Wolf et al., 1993; Hunte et al., 1993; Schulz et al., 1992) are affected by transient clinorotation in leaves of Vicia faba. From these results, the authors suggested that clinorotation is acting as a significant stressor of plant metabolism. These plants, however, are subjected to relatively brief periods of clinorotation (hours) after longer periods (days) of normal, non-clinorotated culture. Use of chronic clinorotation from seed germination has been suggested as more representational of growth in microgravity (Sievers and Hensel, 1981). Plants grown under chronic clinorotation have exhibited changes in growth (Brown et al., 1976), respiration (Dedolph, 1966), and carbohydrate metabolism (Brown and Piastuch, 1994).

Changes in overall protein patterns are indicative of stress in plants (Sachs and Ho, 1986). Extreme stimuli such as freezing and wounding (Guy et al., 1982; Hahn and Walbot, 1989; Theillet et al., 1982) or mild stimuli such as touch (Braam and Davis, 1990) can result in changes in protein expression. In this set of experiments we grew Arabidopsis thaliana under chronic clinorotation to determine the effects of a continuous altered-gravity environment on total soluble protein expression.

\section{Materials and Methods}

Plant Material. Arabidopsis thaliana L. (Heynh.) cv. Columbia seeds were germinated in growth units consisting of $200 \mathrm{ml}$ polycarbonate jars with holes in the top, bottom and sides to allow for shoot growth and root aeration. Metro-Mix 220 (Grace Sierra Horticultural Products, Milpitas, CA) was the rooting medium. Seeds were planted at a density of twenty per growth unit and 
thinned to one plant per growth unit at $15 \mathrm{DAP}$, which was then grown to maturity. Plants grew at $23^{\circ} \mathrm{C}$ under cool white fluorescent lamps $\left(300 \mu \mathrm{mol} \cdot \mathrm{m}^{-}\right.$ $2 \cdot \mathrm{s}^{-1}$ ) with $16 / 8 \mathrm{~h}$ photoperiod cycle.

Soluble Protein Isolation and Analysis. Total soluble proteins were isolated simultaneously with nucleic acids using a modification of the RNA isolation procedure in Wadsworth et al. (1988). One and two-dimensional polyacrylamide gel electrophoresis was performed essentially as in O'Farrell (1975). In vivo-labeling of proteins was done essentially as in Guy et al. (1985) with a $5 \mathrm{~h}$ labeling period beginning $1 \mathrm{~h}$ into the light period.

Computer Analysis of Gels. Four replicate two-dimensional gels were run for each protein sample isolated from leaf and stem tissue of horizontally, stationary or vertically grown Arabidopsis plants. Color or black and white 35 $\mathrm{mm}$ slides of each gel were digitized and analyzed by computer image analysis essentially as in Hruschka and Massie (1983).

\section{Results}

Total soluble proteins isolated from leaf and stem tissue of 24-day old plants were separated by two-dimensional SDS PAGE and examined after silver staining. Figure 1 shows a representative gel from each treatment. Visual analysis identified no significant differences in total soluble protein patterns due to chronic clinorotation. Computer digitization and analysis of the silver-stained gel images yielded an overlapping set of protein patterns with no quantifiable differences (Figure 2). In vivo-labeling and isolation of newly synthesized proteins during rapid plant growth (18 DAP) also distinguished no differences in fluorographs of the gel protein patterns (Figure 3).

Chronic horizontal clinorotation did not result in any gross morphological differences in plant growth or development. Timing of plant development and maturity, plant size and fresh weights were not significantly different between the horizontally clinorotated plants and the vertically rotated and stationary controls plants (data not shown). 


\section{Discussion}

A lack of discernable changes in gross total soluble protein patterns in chronically rotated Arabidopsis stem and leaf tissue appears to be in conflict with recent reports of clinorotation effects on protein expression in Vicia faba leaves (Schulz et al., 1992; Hunte et al., 1993; Wolf et al., 1993). However, in contrast to the present study, those experiments used relatively large plants subjected to short periods of clinorotation. The transient imposition of clinorotation results not only in a nullification of the directional component of gravity but also some mechanical stress, of which the latter would be more pronounced in older, larger plants. Mechanical stimulus is known to result in significant plant responses (Pappas and Mitchell, 1985; Braam et al., 1990). Chronic clinorotation, or growth of a plant from germination under conditions of clinorotation, provides a mechanism for demonstrating effects of clinorotation independent of transitory adaptive factors, which may be especially useful with smaller plant species such as Arabidopsis.

Induction of changes in protein expression is characteristic of many plants under a wide variety of environmental stimuli (Sachs and Ho, 1986). Schulz et al. (1992), Hunte et al. (1993) and Wolf et al. (1993) demonstrated changes in soluble and membrane-bound protein patterns in leaves of transiently clinorotated Vicia faba plants, which were attributed to stress reactions caused by the change in gravity vector. The lack of differences in the protein patterns of the Arabidopsis plants in these experiments indicates an absence of gross stressinducing factors even in the altered gravity environment produced by chronic clinorotation.

\section{Acknowledgments}

The authors wish to thank Dr. William Hruschka for the computer analysis of the gel images. 


\section{References}

BRAAM, J. and R. W. DAVIS: Cell 60, 357-364 (1990).

BROWN, A. H., A. O. DAHL, and D. K. CHAPMAN: Plant Physiol. 57, 358-364 (1976).

BROWN, C. S. and W. C. PIASTUCH: Plant, Cell and Env. 17, 341-344 (1994).

DEDOLPH, R. R., B. R. WILSON, W. CHORNEY, and J. J. BREEN: Plant Physiol. 41, 1520-1524 (1966).

GUY, C. L., K. J. NEIMI, and R. BRAMBL: Proc. Natl. Acad. Sci. USA. 82, 3673-3677 (1985).

HAHN, M. and V. WALBOT: Plant Physiol. 91, 930-938 (1989).

HRUSCHKA, W. R. and D. R. MASSIE: Anal. Chem. 55, 2345-2348 (1983).

HUNTE, C., M. SCHULZ, and H. SCHNABL: J. Plant Physiol. 142, 31-36 (1993).

JOHNSON , S. P. and T.W. TIBBITS: BioScience 18, 655-661 (1968).

O'FARRELL, P. H.: J. Biol. Chem. 250, 4007-4021 (1975).

PAPPAS, T. and C. A. MITCHELL: Plant Physiol. 79, 285-289 (1985).

SACHS, M. M. and T-H. D. HO: Ann. Rev. Plant Physiol. 37, 363-376 (1986).

SCHULZ, M., B. SOLSCHEID, and H. SCHNABL: J. Plant Physiol. 140, 502-507 (1992).

SIEVERS, A. and W. HENSEL: Naturwissenschaften 68, 429 (1981).

THEILLET, C., F. DELPEYROUX, M. FISZMAN, P. REIGNER, and R. ESNAULT: Planta 155, 478-485 (1982).

WADSWORTH, G. J., M. G. REDINBAUGH, and J. G. SCANDALIOS: Ann. Biochem. 172, 279-283 (1988).

WOLF, D., M. SCHULZ, and H. SCHNABL: J. Plant Physiol. 141, 304-308 (1993). 


\section{Legends of Figures}

Figure 1. Representative two-dimensional SDS PAGE gels showing silverstained soluble protein patterns from leaf and stem tissue of 24 day-old Arabidopsis plants. Plant treatments were chronic clinorotation (A), chronic vertical rotation control (B), and stationary vertical control (C). Approximate molecular weights are indicated from standards.

Figure 2. Computer-generated composite images of the digitized slides taken from the silver-stained two-dimensional SDS PAGE gels. Panel A shows the protein pattern for chronic clinorotation, panels $B$ and $C$ show the vertical and stationary controls, respectively, and panel $\mathrm{D}$ is an overlay of all three images. Panels A, B and C are each the composite of four digitized gel images.

Figure 3. Fluorographs of in vivo-labeled soluble proteins from leaf and stem tissue of 18 day-old Arabidopsis plants separated by two-dimensional SDSPAGE. Panel A shows the protein patterns obtained from chronically clinorotated plants and panel B shows the patterns of the vertically-rotated control plants. 


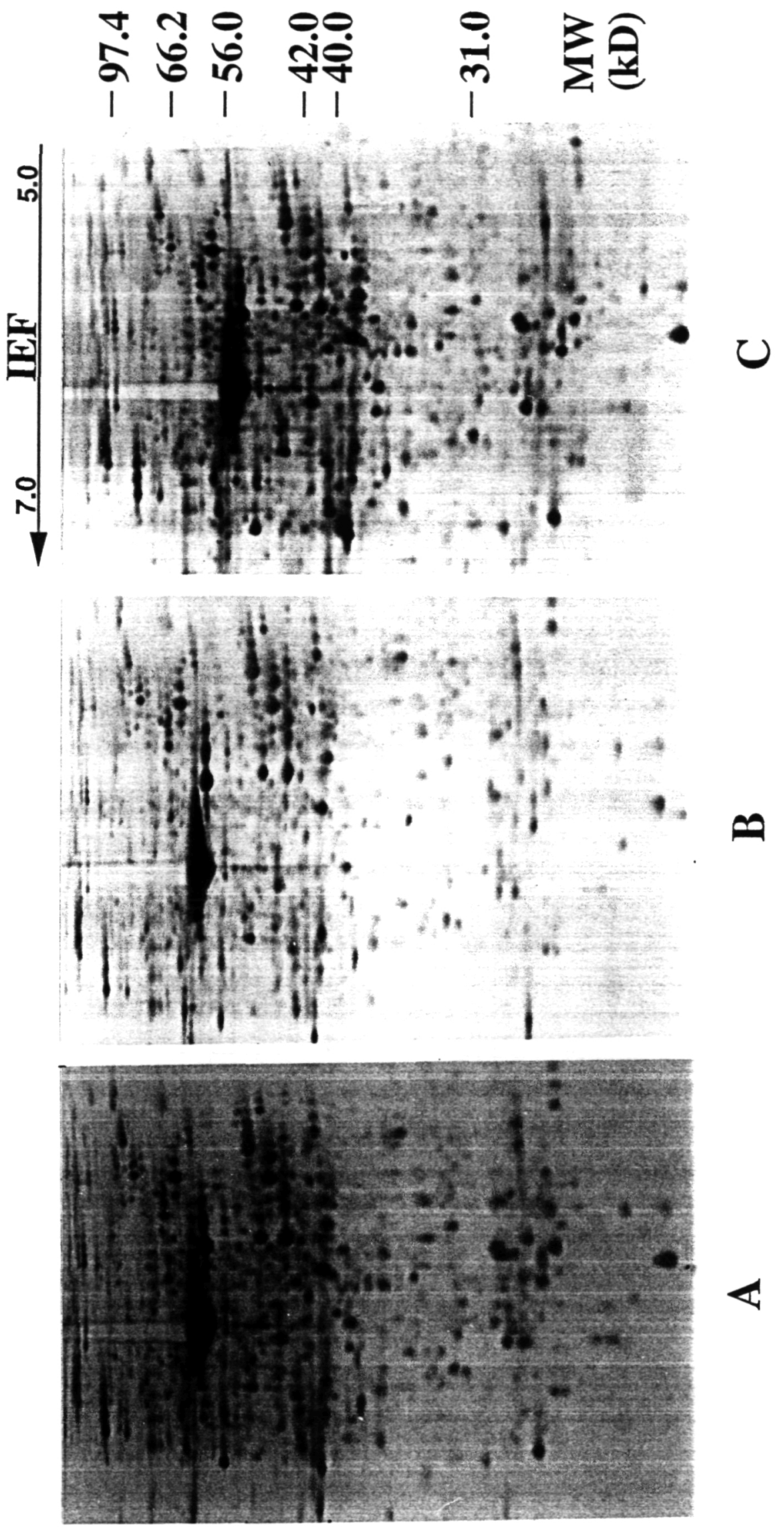




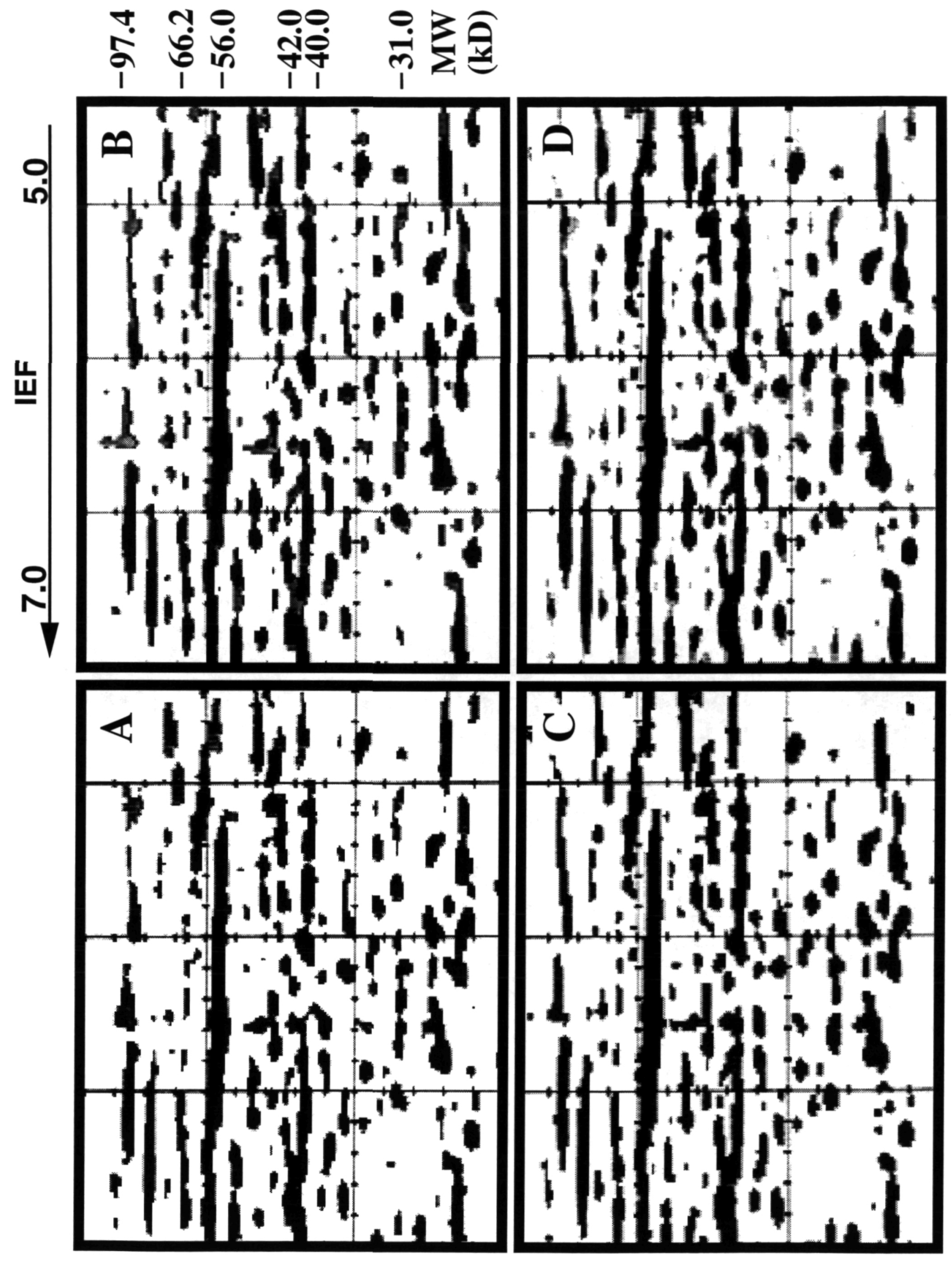




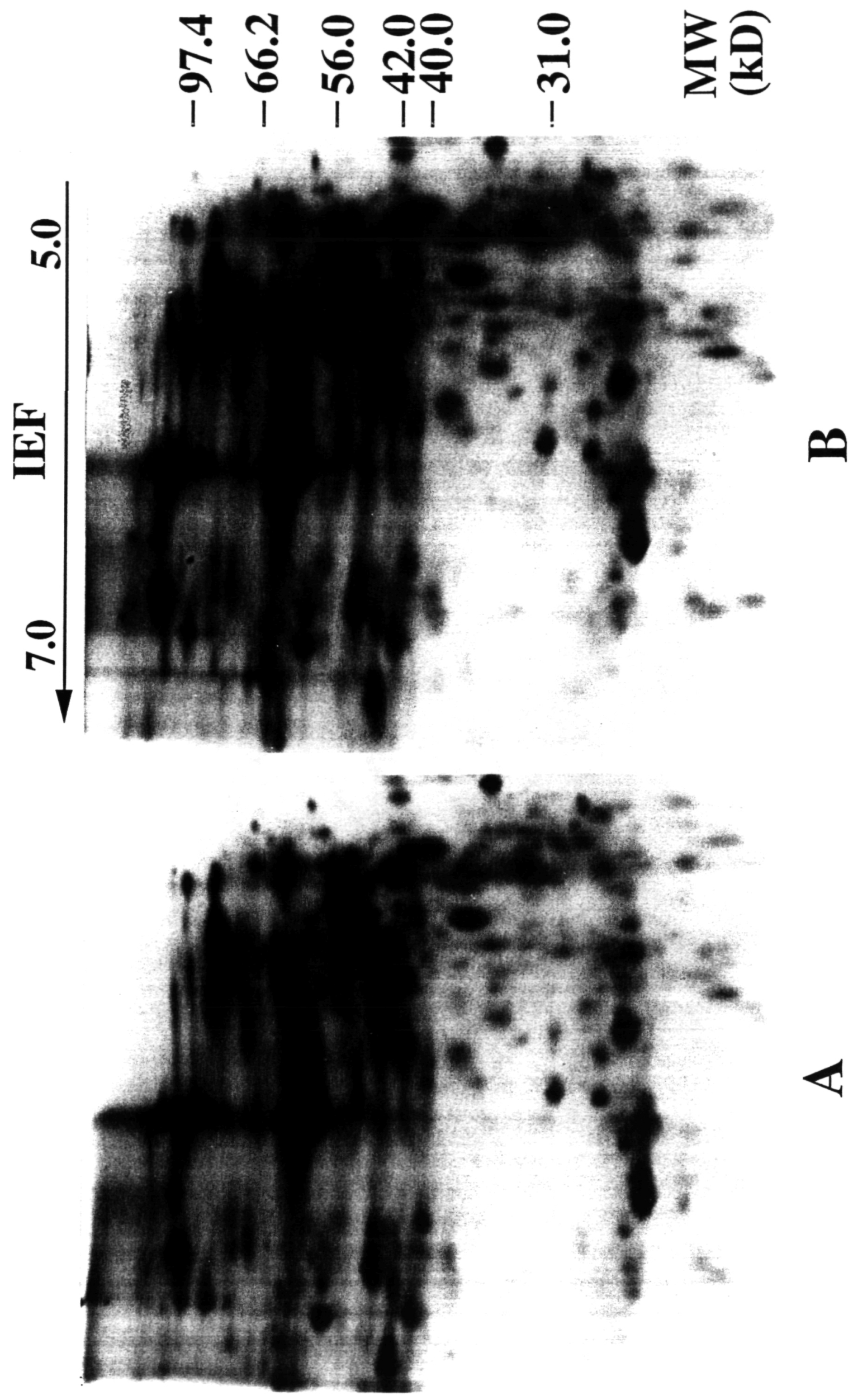

